\title{
The effect of cognitive and affective aspects on usability
}

Heru Prastawa, Udisubakti Ciptomulyono, Moses Laksono-Singgih \& Markus Hartono

To cite this article: Heru Prastawa, Udisubakti Ciptomulyono, Moses Laksono-Singgih \& Markus Hartono (2019): The effect of cognitive and affective aspects on usability, Theoretical Issues in Ergonomics Science, DOI: 10.1080/1463922X.2018.1547458

To link to this article: https://doi.org/10.1080/1463922X.2018.1547458

册Published online: 12 Jan 2019.

Submit your article to this journal $₫$

View Crossmark data \ulcorner 


\title{
The effect of cognitive and affective aspects on usability
}

\author{
Heru Prastawaa,b, Udisubakti Ciptomulyono ${ }^{a}$, Moses Laksono-Singgih ${ }^{\mathrm{a}}$ and \\ Markus Hartonoc \\ aIndustrial Engineering, Institut Teknologi Sepuluh Nopember, Surabaya, Indonesia; ${ }^{b}$ Industrial \\ Engineering, Universitas Diponegoro, Semarang, Indonesia; Industrial Engineering, University of \\ Surabaya, Surabaya, Indonesia
}

\begin{abstract}
Studies on customer's needs, desires and preferences have become highly important in the product design and development process. One consideration in usability is the cognitive aspect, which is related to the accommodation and evaluation of human cognitive capabilities, limitations and tendencies. In addition to the cognitive aspect, a recent study has shown that the affective aspect has been considered in the evaluation of product usability. Thus, both cognitive and affective aspects are deemed to be important for product design and the development process. Inherently, both aspects deliver complete human and product interaction and experience. However, studies that consider the affective process as a complement to the cognitive process for usability are relatively rare. To address this gap, this study discusses how an integrative framework of the cognitive and affective aspects can be applied to a product for usability assessment via empirical studies on e-commerce and e-learning platforms. The sample involved 230 respondents, using purposive sampling. The result shows that both cognitive and affective aspects have a significant effect, although with different weights. The affective aspect has been shown to improve product usability and user's acceptance.
\end{abstract}

\section{ARTICLE HISTORY}

Received 18 March 2018

Accepted 8 November 2018

\section{KEYWORDS}

Cognitive aspect; affective aspect: usability; e-commerce web; e-learning web

\section{Relevance to human factors/Relevance to ergonomics theory}

This study takes the form of both cognitive and affective ergonomics associated with usability. One consideration in usability evaluation is the cognitive aspect, which is related to the accommodation and evaluation of human cognitive capabilities, limitations, and tendencies. In addition to that, a recent study has shown that the affective aspect has been considered in the evaluation of product and service usability. It shows both cognition and affect as the main focus in human centered design have been taken into account for product and service interaction.

This research offers significant contributions. First, the findings can be used to determine the proportion of cognitive and affective aspects in product and service design, particularly those are related to usability evaluation. Product and service designers can gather feedbacks 
on how their design features fit to user satisfaction. Second, for a better usable performance, human-based interactive design such as interface designs for e-learning and e-commerce websites should put focus on the needs for affective and cognitive aspects and features.

\section{Introduction}

In today's competitive markets, a shift has occurred in approaching production orientation, namely, a towards a marketing-oriented approach and ultimately to a customer-oriented approach (Hsiao and Chen 2006). Studies on needs, desires and preferences are highly important in the development of user-centred products (Demirtas, Anagun, \& Koksal 2009). The best practices in user-centred design are summarised in ISO 9241210 (2008).

The cognitive aspect for usability has been implemented into electronic equipment (Han et al. 2001), medical devices, and mobile phones (Seva et al. 2011). Apart from cognition, conclude that emotional needs are also important in the design of new products such as mobile handsets and communication devices. Due to websites being part of the Human Computer Interaction (HCI) field, human behaviour should also be included in website evaluation. In the case of websites, the predominant dimensions of the cognitive aspects include content, ease of use, identification, download delay, trust and made-forthe-medium. For usability in electronic commerce or e-commerce, navigation, interaction, website layout, merchandise information quality and merchandise price are important factors (Li and Li 2011).

The cognitive aspects of usability are always centred on the perceived efficiency and effectiveness of the system. The perception of satisfaction as an integral part of the usability criterion, wherein the affective dimension plays a significant role, has received little attention. In the information systems (IS) domain, it has been suggested that a design's affective dimensions, including colours, images and shapes, affect the overall perception of the information system. Numerous studies conducted decades ago focussed on such emotional aspects as enjoyment (Davis, Bagozzi, \& Warshaw 1992; Head, and Ivanov 2009; van Schaik and Ling 2011; Aranyi and van Schaik 2016). Therefore, although research on acceptance of new technologies has been primarily centred on cognitive dimensions, awareness of the importance of the affective dimension in design, in relation to a growing perception of utility, reveals the need to adopt cognitive-affective models to analyse and design information systems (Kwong et al. 2016).

There has been no definite conclusion about the relationship between aesthetics (affective) and usability. Several of these studies found support for the aesthetics-usability relation (e.g., Lavie and Tractinsky 2004; Hartmann et al. 2008; Quinn and Tran 2010), but other studies could not find this relation (e.g., Hassenzahl 2004; van Schaik and Ling 2009; Alexandre et al. 2012). The combination of the cognitive and affective dimensions is expected to deliver a more comprehensive explanation for user satisfaction, and the relative importance can also be assessed.

A previous measurement model proposed by Kwahk and Han (2002) was very global. The model was bounded by three major factors: the interface features of a product as design variables, the evaluation context consisting of user, product, activity and environment as context variables, and the usability measures as dependent variables. On the contrary, other authors discussed only the cognitive aspect as the key criterion on 
usability assessment (Lioljegren 2006; Li 2012). As a usability evaluation instrument, the question in System Usability Scale (SUS) involves the cognitive and affective aspects together, so it cannot see the magnitude of the weight of influence each aspect holds (Ackerman et al. 2016).

This study proposes a model of usability measurement that integrates both the affective and cognitive aspects in conjunction with usability. The work explores the significance of the influence of cognitive and affective aspects on usability and that of their interactions. Empirical cases in e-learning and e-commerce are examined taking into account that both types of sites are widely used by productive-age users. Respondents for this research are limited to the undergraduate students who are 17-22 years old and the data was collected in June 2017.

In summary, this study has two objectives. The first is to identify the influence of cognitive and affective aspects on e-commerce and e-learning websites; the second is to examine the relationship between cognitive and affective aspects in the usability of e-learning and e-commerce websites. This paper is organised into an introduction, followed by the research methodology, literature review and research hypotheses. Thus, the main contribution of this research is presented, and the paper ends with the discussion and conclusion sections.

\section{Research methodology}

\subsection{Participants}

The participants included 107 males and 123 females between 17 and 22 years of age, for a total of 230 students at a large state university in Indonesia. Participants were recruited according to whether or not they were already familiar with the sites, especially e-learning and e-commerce types. These considerations encouraged a selection of respondents from students, and the sampling plan used is non-probability sampling, more precisely purposive sampling. The mean age was 20 years $(\mathrm{SD}=1.45) ; 46.5 \%$ were male, and 53.5 (77\%) were female. Ethnically, 89.1\% were Javanese and $10.9 \%$ were 'other'. All were students of the X University in Indonesia. Demographic data on this group are shown in Table 1.

The proposed usability measurement model uses the cognitive and affective variables as assessment factors. Certain differences occur in the chosen indicators for the e-learning and e-commerce models. Each model is conceptual, as outlined in the following section. Empirical data were collected through simulations performed in the multimedia laboratory of the Department of Industrial Engineering at the X University.

Table 1. Profile of respondents.

\begin{tabular}{lcc}
\hline Variable & Frequency & \% of total \\
\hline Gender & & \\
$\quad$ Male & 107 & 46.5 \\
Female & 123 & 53.5 \\
Age & & \\
$17-18$ & 18 & 7.8 \\
$17-18$ & 132 & 57.4 \\
$21-22$ & 80 & 34.8 \\
Ethnicity & & \\
Javanese & 205 & 89.1 \\
$\quad$ Other & 25 & 10.9 \\
\hline
\end{tabular}


Questionnaires are made on the selected indicators/dimensions, with consideration of less important indicators being reduced. Based on the results of small group discussions, which consist of potential participants, a priority dimension is determined. The potential participants are students of the final level, and are seen to have sufficient experience and knowledge about usability, e-learning and e-commerce topics.

Discussion results are consulted with experts, such as researchers and ergonomists, as well as web designers who have the competency to be a user or have the knowledge in usability issues. Before the questionnaires were used in data collection, a pilot test was conducted on the questionnaire to assess whether the questionnaire could be understood by the respondents. Data processing was conducted using AMOS 20 software for the Structural Equation Modelling (SEM) method.

\subsection{Subjects and methods}

Electronic learning (e-learning) has been identified as an enabler for people and organisations to keep up with changes in the global economy that now occur in Internet time. In a corporate training context, e-learning refers to training delivered on a computer that is designed to support individual learning or organisational performance goals (Clark \& Mayer 2003). The appearance and the usability of the websites are revealed as the key factors in determining the satisfaction of the students (Luis 2016).

E-learning and e-commerce sites were selected as the case studies based on the argument that e-learning is a learning process while e-commerce is a transaction process. The case study for e-learning is lms.onnocenter.or.id/moodle/, an e-learning site for general public learning. At the time of this study, data retrieval can be accessed through www. cyberlearning.web.id. The case study for e-commerce is Lazada site, which is a B2C (business-to-consumer) effort and is well-known in Indonesia. According to the Lazada is the most famous site and has a percentage recognition of $29.2 \%$.

Cyberlearning was created and developed by Onno Widodo, a figure in the world of Information Technology in Indonesia. E-learning Rakyat (www.cyberlearning.web.id) focusses on Information and Communication Technology learning services using Linux Operating System. Instead of Linux, users can also use Android and participants can request lecture materials through special classes. E-Learning Rakyat is also widely applied in educational institutions by using doodle as a medium of learning.

The selected respondents are eligible students who have understanding and appropriate and continuing of the usability concept. The have allowed passed courses that is relation to usability. Furthermore, before the fulfilled the questioner a briefing is given them. The briefing was carried out by competent lecturers, who qualified in terms of ergonomics and usability knowledge and involved Usability experts. Indicators involved in cognitive and affective aspects are measured based on experience.

This methodology proposed consists of three stages, firstly the measurement/assessment of respondents on the expectations of the cognitive and affective aspects of usability. The next stage, respondents are given time to be more familiar with the web that is used as an object for 1 week to gain experience. The next stage is an assessment/measurement of the perception of the influence of cognitive and affective aspects on usability from familiar objects based on experience.

Scenarios for the user of e-commerce sites are provided in the form of product search activities to enter selected products into the purchase cart. As for the users of e-learning 
sites, respondents perform tasks/scenarios that have been determined to answer questions that have been prepared previously. The implementation of both scenarios is given sufficient rest time to avoid bias.

The students, as respondents, should be familiar with the e-learning and e-commerce sites evaluated for at least one week during data retrieval. In addition, also completed the face validity to make sure that test should be measured is good. This is done by watching his/her face as participants performing the tasks that have been prepared in the scenarios.

The survey was conducted in the multimedia laboratory using online questionnaires. The potential respondents were approached and asked to participate. The interviewer briefly introduced him/herself and explained the purpose of the research and the survey procedures. The data for this research were collected using the questionnaires. The respondents were randomly selected students (107 males and 123 females) who use e-learning sites.

$\mathrm{H}_{1}$ :Cognitive aspect positively influences usability

$\mathrm{H}_{2}$ :Affective aspect positively influences usability

$\mathrm{H}_{3}$ :Cognitive and affective aspects are significantly interconnected

Three expected and perceived hypotheses were tested on an e-learning website and on an e-commerce website. The expected are expressed as a degree of probability that an event will occur, whereas the perceived are assessed based on the user experience in accessing the site. The selection of the tested expected and perceived was conducted to evaluate the consistency of the desired expectations and applications on the site chosen for the case study.

\subsection{Validity and reliability test}

Before testing the hypotheses of each case, firstly, we underwent an examination of the statistical testing, including a test of internal consistency of reliability and confirmatory. Internal consistency of reliability represents the degree to which items within a dimension measure the same constructs as one another. The test is based on Cronbach's alpha. The coefficient of Cronbach's alpha's reliability normally ranges between 0 and 1 . Should the value of Cronbach's alpha coefficient be closer to 1.0, the internal consistency of the items is greater. The analysis of the confirmatory factor was performed to assess the validity of the constructs. To judge the model's fit, this study employed the comparative fit index (CFI), the goodness of fit index (GFI), the normed fit index (NFI), and the root mean square error of approximation (RMSEA). CFI is the recommended index of an overall fit and is commonly applied to measure the fitness of one model compared to another. Further, NFI is frequently used to measure the degree of improvement of a particular model's fitness with a base model, and RMSEA delivers information on the discrepancy per degree of freedom of a particular model.

In order to determine the relationship between the constructs in the proposed mode, the structural equation model was tested using AMOS 20 with the default maximum likelihood estimation method. Except the $\chi^{2}$, the fit indices considered in this study met the recommended level of the acceptable fit. The chi-square was discovered to be too sensitive to this sample size, and, therefore, $\chi^{2}$ ratio to its freedom degree $\left(\chi^{2} / \mathrm{df}\right)$ is used under the condition that an acceptable fit is identified for the proposed model. 


\section{Literature review and research hypotheses}

We propose three hypotheses according to the current research on the interrelationship among the three constructs, namely:

\subsection{Cognitive aspect and usability}

According to Han et al. (2001), the cognitive process consists of three stages: perception, memorisation, and control. Perception or cognition consists of usability dimensions that assess how well users understand and interpret the interface product or system. Certain dimensions, such as directness, explicitness, model quality, observability, responsiveness and simplicity, are important in the design and evaluation of how the system status information is sent to the user via an interface (e.g., display panel, label, icon and indicator status). The memorability dimension explains how quickly users become familiar with the product and how well they remember it. Learnability and memorability are typical dimensions of usability in this category, the others being consistency, familiarity, informativeness and predictability.

The next dimension used in checking terminology is used to label control and display behavioural interactions. The categories of control or action, which represent a dimension that describes the user's control activities and results, including accessibility, adaptability, controllability, effectiveness, efficiency and several other dimensions. Consequently, it is critical to achieve user's acceptance, accessibility and usability of products and systems (Johnson and Johnson 2006).

Based on the customer's point of view, through co-creation, a customer can create value that is deemed of primary importance to him or her by fulfiling his or her affective and cognitive needs, i.e., user's experience (Zhou et al. 2011). The current research has demonstrated that cognitive overload can be an important aspect of usability (Adam 2007).

$\mathrm{H}_{1}$ : Cognitive aspect positively influences usability.

\subsection{Affective aspect and usability}

In addition to evaluating the usability aspects of the product, other aspects, such as image and impression or assessment of product taste, also affect the user. The consumer's choice of the product depends on a number of multidimensional factors, including affective, perceptual and behavioural dimensions, that designers must continue to strive to understand. These elements include shapes, colours, materials, ornaments and texture. A round shape connotes tenderness and continuity, and a sharp angle is perceived as sudden or even unsafe (Lewalski 1998; Fagerberg, Stahl, and Hook 2004). The emotional needs of consumers, or the so-called Kansei needs, have become important factors in product design (Huang, Chen, \& Khoo 2012). In the service industry, the emotional dimension has been widely studied, including examining customer perspective, in order to measure service quality in the logistics field (Meng et al. 2010), and the Nordic perspective of evaluating logistics service quality in terms of the dimensions of logistics outcome quality and process quality has also been studied.

Several studies have investigated the relation between usability and aesthetics (Hassenzahl and Monk 2010). A number of these studies found evidence for the aesthetics-usability relation (e.g., Hartmann et al. 2008; Quinn and Tran 2010), but other studies could not find 
this relation (e.g., Hassenzahl 2004; van Schaik and Ling 2009). Norman (2004) explains three aspects of design that can induce affective results in users: appearance (Visceral), behaviour and function (behavioural), and image and brand considerations (Reflective), while Kim et al. (2016) distinguishes the affective aspect between being primitive (e.g. colour, texture), descriptive (e.g. delicacy, simplicity) and evaluative (e.g. attractiveness, luxuriousness).

This study focusses on measuring visceral affect, by targeting representations of emotions felt while interacting with the website by choosing the establishing indicators. These indicators that are built to determine its contribution as a construct of affective aspects is used in the measurement model.

Considering to the trait affect concept, according to Berry et al. (2005), defined as a tendency to respond to specific classes of stimuli in a predetermined, affect-based manner. High trait positive affect (TPA) is characterised by the tendency to experience positively activated emotions in general, such as excitement, high energy, joy, and enthusiasm. In this study the emotion traits such as appealing, pleasant, and comfort were used.

$\mathrm{H}_{2}$ : Affective aspect positively influences usability.

\subsection{Interaction between cognitive and affective aspects}

According to the assessment theory, the same stimulus of a product can produce different affective responses from various individuals based on the product's perceived meaning and relevance to the individual. The image is only a component of the affective aspect, which is related to a person's emotions. The affective dimension is also used as one of the elements relevant to analysing the user experience (Heidig, Müller, \& Reichelt 2015).

Rubin and Chisnell (2008) explain that a product can be said to be usable if, in its use, no frustration is found. Some general factors can be used as benchmarks in measuring usability, namely learnability, efficiency, memorability, errors and satisfaction (Nielsen 1993). This study attempted to confirm that cognitive, cognitive-affective and affective were factors influencing the perceived usability.

$\mathrm{H}_{3}$ : Cognitive and affective aspects are significantly interconnected

\subsection{Conceptual model of usability for e-learning and e-commerce}

The conceptual model proposed by Asil et al. (2009) and Han at al. (2001) was selected to incorporate the cognitive and affective aspects. Han et al. (2001) described the dimensions used to evaluate the usability for consumer of electronics products and divided them into two categories, i.e., performance and impressions. Cognitive in the understanding as performances were grouped in perception/cognition with six indicators (Directness, Explicitness, Modelessness, Observability, Responsiveness, Simplicity); learning/memorisation with six indicators (Consistency, Familiarity, Informativeness, Learnability, Memorability, Predictability); and control/action with 11 indicators (Accessibility, Adaptability, Controllability, Effectiveness, Efficiency, Error prevention, Flexibility, Helpfulness, Multithreading, Recoverability, Task conformance).

Han et al. (2001) also used the impression dimension term as an affective understanding and grouped in a basic sense with eight indicators (Shape, Colour, Brightness, Texture, 
Translucency, Balance, Heaviness, Volume); description of image with 10 indicators (Metaphoric image design, Elegance, Granularity, Harmoniousness, Luxuriousness, Magnificence, Neatness, Rigidity, Salience, Dynamicity); and evaluative feeling with seven indicators (Acceptability, Comfort, Convenience, Reliability, Attractiveness, Preference, Satisfaction).

On the other hand, Asil (2010) proposed 12 dimensions that can be used to evaluate e-learning without distinguishing cognitive and affective factors. These dimensions include: Error prevention, Visibility, Flexibility, Course management, Interactivity, Feedback and Help, Accessibility, consistency and functionality, Assessment strategy, Memorability, Completeness, Aesthetic and Reducing redundancy. Previously, Asil (2009) proposed an assessment methodology for the usability of web-based information systems, based on the ServQual model. The indicators or dimensions used from Han et al. (2001) and Asil (2010) models are labelled in Table 2 for e-learning and Table 4 for e-commerce.

In order to elaborate more detail of conceptual model application in e-learning, each aspect or factor is elaborated in accordance with e-learning indicators. Two aspects are used to measure usability performance: the cognitive and affective aspects. The cognitive aspects consist of error prevention (e.g., the ability to easily undo selections); interactivity, feedback and help (e.g., performance delivered in a timely manner); learnability (presented in organised chunks to support learnability); flexibility (an online learning environment with the addition of resources); memorability (cognitive load reduced by creating familiarity); easy navigation; logical navigation; undesirable site direction; and an easy escape option.

This is to determine the effects of the cognitive and affective aspects of usability on e-learning, to determine the relationship between the cognitive and affective aspects in e-learning, and to create recommendations based on the results of the usability measurements. Thus, the measurement results can be used as a reference in usability improvement for e-learning sites. The conceptual model used in this research is presented in Figure 1

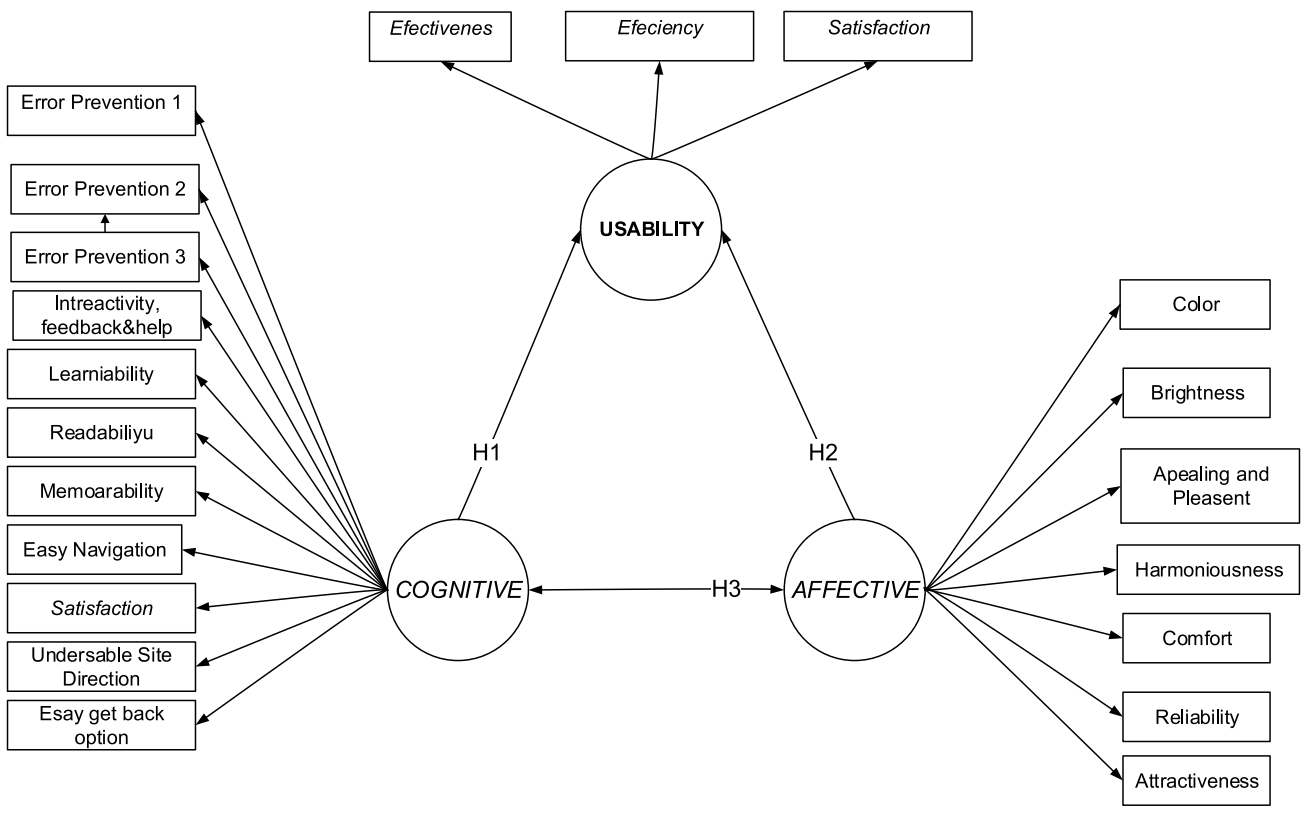

Figure 1. Conceptual model of usability for e-learning. 
Table 2. Variables and indicators for e-learning.

\begin{tabular}{lll}
\hline Variable & \multicolumn{1}{c}{ Cognitive indicator } & Abbreviation \\
\hline X1 & Error Prevention 1 & EP1 \\
X2 & Error Prevention 2 & EP2 \\
X3 & Error Prevention 3 & EP3 \\
X4 & Interactivity, feedback and help & INFH \\
X5 & Learnability & LEAR \\
X6 & Readable & READ \\
X7 & Memorable & MEMO \\
X8 & Easy Navigation & ENAV \\
X9 & Logical Navigation & LNAV \\
X10 & USite Direction & UNSD \\
X11 & Easy-to-Go-Back Option & EGBO \\
Variable & Affective indicator & \\
X12 & Color & COLO \\
X13 & Brightness & BRIG \\
X14 & Harmoniousness & HARM \\
X15 & Salience & SALI \\
X16 & Appealing and Pleasant & APPL \\
X17 & Comfort & COMF \\
X18 & Reliability & RELI \\
X19 & Attractiveness & ATTR \\
\hline
\end{tabular}

and Table 2. The elements (questions) on the questionnaire of Indicator variables are seen in the table in the Appendix

According to Korgaonkar et al. (1999), the basic purposes of e-commerce sites can be classified into four types, namely, entertainment, destination information, communication and trafficking (commerce). E-commerce sites displayed by a company should have high-quality systems, information and services, because these factors significantly impact the success of e-commerce (De Lone \& McLean 2004).

A fifth addition to these quality aspects was proposed by Tsai et al. (2010), who argued that additional quality website design is needed to attract the attention of customers. This statement is in accordance with the work of Bonnardel et al. (2011), which states that the development of design systems at these sites should not only focus on ease of use, but should also consider that the site design should be more interesting to the users. According to Han et al. (2001), design and evaluation of product usability should consider performance (cognitive) and impression (affective) factors.

The cognitive variables based on the assessment indicators reported by Asil et al. (2010) and Lee and Kozar (2012) consist of: error prevention; interactivity, feedback and help; readability; content relevance; and consistency. The affective variables based on assessment indicators from Han et al. (2001) and Park and Han (2013) include colour, brightness, harmoniousness, comfort, reliability, acceptability and neatness. The conceptual model used in this research is presented in Figure 2. Variables and indicators are presented in Table 3. The elements (questions) on the questionnaire of Indicator variables are in the table in the Appendix.

\section{Results}

\subsection{Usability analysis on e-learning website}

The participants were asked to evaluate the importance of individual usability indicators. The construct of the cognitive aspect has 11 indicators, and that of the affective aspect has 


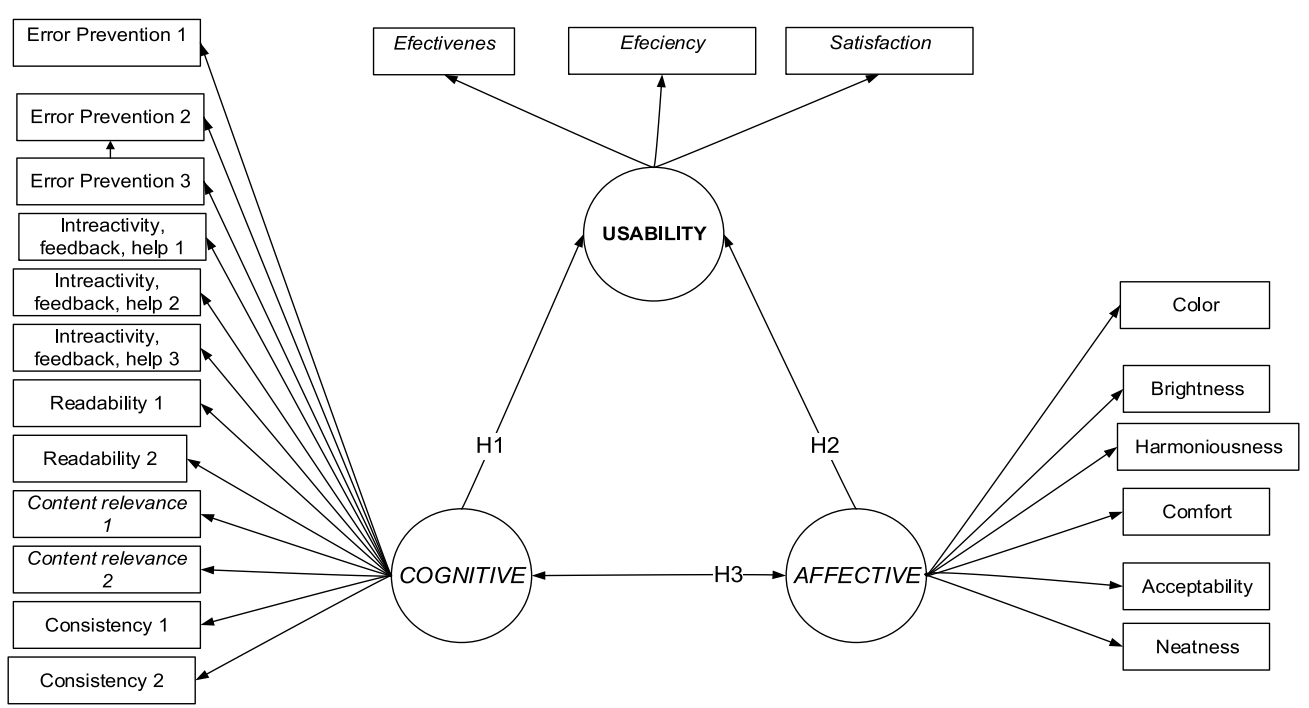

Figure 2. Conceptual model of usability for e-commerce.

Table 3. Variables and indicators for e-commerce.

\begin{tabular}{lll}
\hline Variable & \multicolumn{1}{c}{ Cognitive indicator } & Abbreviation \\
\hline X1 & Error Prevention 1 & EP 1 \\
X2 & Error Prevention 2 & EP 2 \\
X3 & Error Prevention 3 & EP 3 \\
X4 & Interactivity, feedback and help 1 & IFH 1 \\
X5 & Interactivity, feedback and help 2 & IFH 2 \\
X6 & Interactivity, feedback and help 3 & IFH 3 \\
X7 & Readability 1 & READ 1 \\
X8 & Readability 2 & READ 2 \\
X9 & Content Relevance 1 & CR 1 \\
X10 & Content Relevance 2 & CR 2 \\
X11 & Consistency 1 & CONS 1 \\
X12 & Consistency 2 & CONS 2 \\
Variable & Affective indicator & \\
X13 & Color & COLO \\
X14 & Brightness & BRGT \\
X15 & Harmoniousness & HARM \\
X16 & Comfort & COMF \\
X17 & Acceptability & ACCP \\
X18 & Neatness & NEAT \\
\hline
\end{tabular}

eight indicators. The full model achieves a fit condition after four iterations, and the results are shown in Tables 4-7 and Figure 3.

\subsubsection{Internal consistency reliability test}

Table 4 summarises the results of the internal consistency reliability tests with respect to the constructs used in the current research (Cronbach's alpha values). The Cronbach's alpha values range from 0.747 to 0.847 . With a cut-off value limit of 0.70 , the reliability test results show that usability variables, cognitive and affective factors are worthwhile, which means that the indicators of these variables can consistently represent the formation variable developed. 


\subsubsection{Confirmatory factor analysis}

Table 5 shows the results of the confirmatory factor analysis. All model fits were acceptable on the basis of all indicators exceeding the cut-off value limit of 0.50 , and, according to the literature, the validity of the measurements in the current study met the criteria.

Table 4. Results of Cronbach's alpha test.

\begin{tabular}{|c|c|c|c|c|c|}
\hline \multirow[b]{2}{*}{ Construct } & \multirow[b]{2}{*}{ Number of items } & \multicolumn{2}{|c|}{ Expectation of e-learning web } & \multicolumn{2}{|c|}{ Perception of e-learning web } \\
\hline & & Cronbach's alpha & $\sqrt{A V E}$ & Cronbach's alpha & $\sqrt{A V E}$ \\
\hline Cognitive aspect & 10 & 0.847 & 0.708 & 0.890 & 0.707 \\
\hline Affective aspect & 6 & 0.763 & 0.706 & 0.837 & 0.727 \\
\hline Usability & 3 & 0.784 & 0.707 & 0.747 & 0.729 \\
\hline
\end{tabular}

Note: AVE = average variance extracted.

Table 5. Results of confirmatory factor analysis.

\begin{tabular}{|c|c|c|c|c|c|c|c|c|c|}
\hline \multirow[b]{2}{*}{ Construct } & \multirow[b]{2}{*}{ Item } & \multicolumn{4}{|c|}{ Expectation of e-learning website } & \multicolumn{4}{|c|}{ Perception of e-learning website } \\
\hline & & SRW & SE & CR & $\left.P^{*}\right)$ & SRW & SE & CR & $\left.P^{*}\right)$ \\
\hline \multirow[t]{10}{*}{ Cognitive aspect } & & 0.580 & & & & 0.536 & & & \\
\hline & EP1 & 0.700 & .149 & 6.178 & $* * *$ & 0.543 & .119 & 9.405 & $* * *$ \\
\hline & EP2 & 0.616 & .160 & 7.113 & *** & 0.609 & .103 & 8.467 & $* * *$ \\
\hline & EP3 & 0.588 & .185 & 6.603 & $* * *$ & 0.552 & .123 & 8.108 & $* * *$ \\
\hline & LEAR & 0.703 & .157 & 5.957 & $* * *$ & 0.523 & .119 & 8.843 & *** \\
\hline & MEMO & 0.629 & .149 & 5.770 & $* * *$ & 0.565 & .115 & 9.089 & *** \\
\hline & ENAV & 0.714 & .163 & 6.374 & $* * *$ & 0.699 & .116 & 9.527 & $* * *$ \\
\hline & LNAV & 0.636 & .157 & 6.367 & $* * *$ & 0.651 & .097 & 8.786 & $* * *$ \\
\hline & UNSD & 0.689 & .157 & 6.367 & $* * *$ & 0.591 & & & $* * *$ \\
\hline & EGBO & 0.507 & & & $* * *$ & 0.507 & .118 & 8.272 & $* * *$ \\
\hline \multirow[t]{8}{*}{ Affective aspect } & & 0.322 & & & $* * *$ & 0.62 & & & \\
\hline & COLO & 0.674 & & & $* * *$ & 0.529 & & & $* * *$ \\
\hline & BRIG & 0.517 & .122 & 8.075 & $* * *$ & 0.558 & .072 & 8.491 & $* * *$ \\
\hline & HARM & 0.728 & .135 & 7.748 & $* * *$ & 0.609 & .091 & 10.182 & $* * *$ \\
\hline & SALI & 0.743 & .120 & 7.073 & $* * *$ & & & & \\
\hline & APPL & 0.610 & .149 & 5.830 & $* * *$ & 0.575 & .127 & 8.343 & $* * *$ \\
\hline & COMF & 0.783 & .127 & 7.487 & $* * *$ & 0.633 & .091 & 10.777 & $* * *$ \\
\hline & ATTR & 0.732 & .128 & 6.683 & $* * *$ & 0.595 & .087 & 9.706 & $* * *$ \\
\hline \multirow[t]{3}{*}{ Usability } & $\mathrm{EFT}$ & 0.658 & & & $* * *$ & 0.625 & & & $* * *$ \\
\hline & $\mathrm{EFC}$ & 0.793 & .165 & 7.652 & $* * *$ & 0.775 & .165 & 7.652 & $* * *$ \\
\hline & SAT & 0.658 & .123 & 7.567 & $* * *$ & 0.657 & .123 & 7.567 & $* * *$ \\
\hline
\end{tabular}

Note: $\left.{ }^{* *}\right)$ Significant with a significant value of 0.05 .

$\mathrm{CR}=$ construct reliability; $\mathrm{SE}=$ scalar estimates; $\mathrm{SRW}=$ standardised regression weight.

Table 6. Fit indices for the research model.

\begin{tabular}{|c|c|c|c|c|c|c|}
\hline \multirow[b]{2}{*}{$\begin{array}{l}\text { Goodness of } \\
\text { fit Index }\end{array}$} & \multicolumn{3}{|c|}{ Expectation of e-learning website } & \multicolumn{3}{|c|}{ Perception of e-learning website } \\
\hline & $\begin{array}{l}\text { Cut-off } \\
\text { Value }\end{array}$ & Values & Note & $\begin{array}{l}\text { Cut-off } \\
\text { Value }\end{array}$ & Value & Note \\
\hline Chi-square & $<93.945$ & 142.218 & Marginal fit & $<93.945$ & 224.190 & Marginal fit \\
\hline CMINDF & $\leq 2.0$ & 1.948 & Good fit & $\leq 2.0$ & 1.525 & Good fit \\
\hline Probability & $\geq 0.05$ & 0.000 & Marginal fit & $\geq 0.05$ & 0.000 & Marginal fit \\
\hline GFI & $\geq 0.9$ & 0.919 & Good fit & $\geq 0.9$ & 0.910 & Good fit \\
\hline RMSEA & $\leq 0.08$ & 0.065 & Good fit & $\leq 0.08$ & 0.049 & Good fit \\
\hline AGFI & $\geq 0.9$ & 0.884 & Marginal fit & $\geq 0.9$ & 0.883 & Marginal fit \\
\hline TLI & $\geq 0.9$ & 0.915 & Good fit & $\geq 0.9$ & 0.953 & Good fit \\
\hline $\mathrm{NFI}$ & $\geq 0.9$ & 0.871 & Marginal fit & $\geq 0.9$ & 0.892 & Marginal fit \\
\hline
\end{tabular}

Note: CMINDF: the minimum sample discrepancy function/degree of freedom.

$\mathrm{AGFI}=$ Adjusted Goodness of Fit Index; GFI = goodness of fit index; NFI = normed fit index; RMSEA = root means square error of approximation; TLI=Tucker Lewis Index. 


\subsubsection{Test of the measurement model}

Table 6 indicates the level of acceptable fit and the fit indices for the proposed research model in the current study.

Table 6 shows marginal fits for chi-square and the probability of the e-learning sites because the chi-square and the probability are highly sensitive to the sample size. Each e-learning feasibility test of a site considers four criteria for a good fit: CMINDF, GFI, RMSEA and TLI. A category with a marginal fit in a careful review of the model means that the model can be improved by including additional indicators, and if the criteria suggest a good fit, then the model can be said to fit.

\subsubsection{Test of the structural model}

The results of the hypothesis tests and the path coefficients of the proposed research model are shown in Table 7 and Figure 3 below.

In the case of expectations for an e-learning website, of the 11 preferred indicators of cognitive variables, only two indicators are excluded, namely, interactivity, feedback and help (IFH) and readability (READ), and, for the affective variables of seven indicators, only one, reliability (RELI), was not supported. The indicator that has the greatest loading factor among the cognitive variables is Easy Navigation, with a value of 0.714 . Easy navigation is an indicator that measures whether the user can easily use the navigation on the website.

The indicator with the greatest loading factor for affective variables for the website is comfort, with a value of 0.783 . Comfort demonstrates that the indicators of the variables

Table 7. Hypothesis testing results.

\begin{tabular}{lcccccc}
\hline & & \multicolumn{2}{c}{ EOEL } & \multicolumn{2}{c}{ POEL } & Result \\
\cline { 3 - 6 } Hypothesis & Path & SPC & t-Value & SPC & t-Value & Supported (two-tailed test) \\
\hline $\mathrm{H}_{1}$ & $\mathrm{CF} \Longrightarrow \mathrm{US}$ & 0.536 & $3.378^{* * *}$ & 0.58 & $4.156^{* * *}$ & Sup \\
$\mathrm{H}_{2}$ & $\mathrm{AF} \Longrightarrow \mathrm{US}$ & 0.202 & $2.582^{* * *}$ & 0.62 & $1.271^{* * *}$ & Supported (two-tailed test) \\
$\mathrm{H}_{3}$ & $\mathrm{CF} \Longrightarrow \mathrm{AF}$ & 0.104 & $4.492^{* * *}$ & 0.14 & $5.102^{* * *}$ & Supported (two-tailed test) \\
\hline
\end{tabular}

Notes: $\mathrm{AF}=$ Affective factors; $\mathrm{CF}=$ Cognitive factors; $\mathrm{EOEL}=$ Expectation of e-learning website; $\mathrm{POEL}=$ Perception of e-learning website; $S P C=$ Standardised path coefficient; US = Usability.

***) Significant with a significant value of 0.05 .

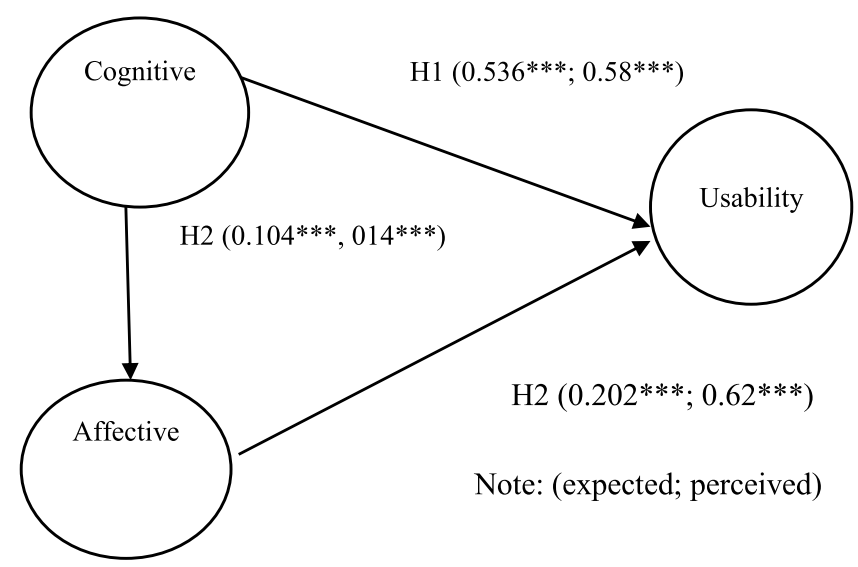

Figure 3. Standardised path coefficients for e-learning. 
consistently represent the formation variables developed. Based on the table, the Cronbach's alpha value is greater than 0.70 , which suggests that indicators of the variables consistently represent those variables.

Table 6 shows that hypotheses 1,2 and 3 are accepted because they have significance values of below 0.05 . Three hypotheses are supported by the data, as cognitive and affective factors directly predicted the usability which reinforces the interrelation between cognitive and affective factors.

In the case of perception of an e-learning website, of the 11 preferred indicators of cognitive variables, the following are not qualified: interactivity, feedback and help, and readability. For the seven indicators of affective variables, reliability was not supported. The indicator that has the greatest loading factor for cognitive variables is easy navigation, with a value of 0.6999 , and, for affective variables, the greatest factor is comfort, with a value of 0.783. Based on the table, the Cronbach's alpha value is greater than 0.70. Hypotheses 1,2 and 3 are accepted because they have significance values of below 0.05 . Cognitive factors have a positive influence on the usability of an e-learning website, with a value of 0.545 , which is greater than that of the affective factor, which is 0.322 .

\subsection{E-commerce website}

The participants were asked to evaluate the importance of individual usability indicators. The construct of cognitive aspects contains 12 indicators, and that of the affective aspects has six indicators. The full model achieves a fit condition after four iterations, and the results are shown in Tables $8-11$ and Figure 4.

\subsubsection{Internal consistency reliability test}

Table 8 summarises the results of the internal consistency reliability tests with respect to constructs used in the current research (Cronbach's alpha values). The Cronbach's alpha values ranged from 0.704 to 0.791 .

\subsubsection{Confirmatory factor analysis}

Table 9 shows the results of the confirmatory factor analysis. All model fits were acceptable on the basis of all indicators exceeding the cut-off value limit of 0.50 , and, according to the literature, the validity of the measurements in the current study met the criteria.

Test of the measurement model

Table 10 indicates the level of acceptable fit and the fit indices for the proposed research model in the current study.

Table 8. Results of Cronbach's alpha test.

\begin{tabular}{|c|c|c|c|c|c|c|}
\hline \multirow[b]{2}{*}{ Construct } & \multirow[b]{2}{*}{ Number of items } & \multicolumn{2}{|c|}{ EOEC website } & \multirow[b]{2}{*}{ Number of items } & \multicolumn{2}{|c|}{ POEC website } \\
\hline & & Cronbach's alpha & $\sqrt{A V E}$ & & Cronbach's alpha & $\sqrt{A V E}$ \\
\hline Cognitive & 5 & 0.704 & 0.667 & 6 & 0.728 & 0.689 \\
\hline Affective & 2 & 0.712 & 0.577 & 5 & 0.744 & 0.572 \\
\hline Usability & 3 & 0.773 & 0.796 & 3 & 0.791 & 0.658 \\
\hline
\end{tabular}

Note: $\mathrm{AVE}=$ Average variance extracted; $\mathrm{EOEC}=$ Expectation of e-commerce website; $\mathrm{POEC}=$ Perception of e-commerce website. 
Table 9. Results of confirmatory factor analysis.

\begin{tabular}{|c|c|c|c|c|c|c|c|c|c|}
\hline \multirow[b]{2}{*}{ Construct } & \multirow[b]{2}{*}{ Item } & \multicolumn{4}{|c|}{ Expectation of e-commerce website } & \multicolumn{4}{|c|}{ Perception of e-commerce website } \\
\hline & & SRW & SE & $\mathrm{CR}$ & $\left.\mathrm{P}^{*}\right)$ & SRW & SE & CR & $\left.P^{*}\right)$ \\
\hline \multirow[t]{9}{*}{ Cognitive Factor } & & 0.536 & & & $* * *$ & 0.802 & & & $* * *$ \\
\hline & EP1 & 0.625 & .149 & 6.105 & *** & 0.622 & .163 & 7.184 & $* * *$ \\
\hline & EP2 & 0.662 & .156 & 5.556 & $* * *$ & 0.534 & .148 & 6.890 & $* * *$ \\
\hline & EP3 & 0.564 & .159 & 5.514 & *** & & & & \\
\hline & $\mathrm{IFH} 2$ & & & & & 0.597 & .151 & 6.592 & $* * *$ \\
\hline & RE1 & & & & & 0.559 & .161 & 6.849 & $* * *$ \\
\hline & CR2 & & & & & 0.535 & .155 & 6.675 & $* * *$ \\
\hline & CS1 & 0.516 & .130 & 6.620 & $* * *$ & 0.581 & & & $* * *$ \\
\hline & CS1 & 0.502 & & & $* * *$ & & & & \\
\hline \multirow[t]{7}{*}{ Affective Factor } & & 0.207 & & & $* * *$ & 0.207 & & & 0.204 \\
\hline & $\mathrm{COL}$ & 0.552 & & & $* * *$ & 0.552 & & & $* * *$ \\
\hline & BRT & 0.692 & .187 & 6.861 & $* * *$ & & & & \\
\hline & HAR & & & & & 0.692 & .172 & 8.020 & $* * *$ \\
\hline & SAL & & & & & 0.670 & .151 & 7.699 & $* * *$ \\
\hline & COM & & & & & 0.689 & .158 & 7.614 & $* * *$ \\
\hline & ATT & & & & & 0.675 & .150 & 7.518 & $* * *$ \\
\hline \multirow[t]{3}{*}{ Usability } & EFT & 0.652 & & & $* * *$ & 0.625 & & & $* * *$ \\
\hline & $\mathrm{EFC}$ & 0.744 & .220 & 5.660 & $* * *$ & 0.775 & .122 & 9.196 & $* * *$ \\
\hline & SAT & 0.596 & .160 & 6.324 & $* * *$ & 0.657 & .129 & 8.257 & $* * *$ \\
\hline
\end{tabular}

Note: $\left.{ }^{* *}\right)$ Significant with significant value of 0.05 .

$\mathrm{CR}=$ construct reliability; $\mathrm{SE}=$ scalar estimates; $\mathrm{SRW}=$ standardised regression weight.

Table 10. Test of the measurement model.

\begin{tabular}{lcclccl}
\hline $\begin{array}{l}\text { Goodness of } \\
\text { fit Index }\end{array}$ & Cut-off Value & Value & Note & $\begin{array}{c}\text { Cut-off } \\
\text { Value }\end{array}$ & Value & Note \\
\hline Chi-square & $<43.773(5 \%, 85)$ & 53.031 & Marginal fit & $<93.945$ & 142.218 & Marginal fit \\
CMINDF & $\leq 2.0$ & 1.768 & Good fit & $\leq 2.0$ & 1.948 & Good fit \\
Probability & $\geq 0.05$ & 0.006 & Marginal fit & $\geq 0.05$ & 0.000 & Marginal fit \\
GFI & $\geq 0.9$ & 0.956 & Good fit & $\geq 0.9$ & 0.919 & Good fit \\
RMSEA & $\leq 0.08$ & 0.058 & Good fit & $\leq 0.08$ & 0.065 & Good fit \\
AGFI & $\geq 0.9$ & 0.919 & Good fit & $\geq 0.9$ & 0.884 & Marginal fit \\
TLI & $\geq 0.9$ & 0.940 & Good fit & $\geq 0.9$ & 0.915 & Good fit \\
NFI & $\geq 0.9$ & 0.914 & Good fit & $\geq 0.9$ & 0.871 & Marginal fit \\
\hline
\end{tabular}

Note: AGFI = Adjusted Goodness of Fit Index; CMINDF = the minimum sample discrepancy function/degree of freedom; $\mathrm{GFI}=$ goodness of fit index; NFI = normed fit index; RMSEA = root means square error of approximation; $\mathrm{TLI}=$ Tucker Lewis Index.

Table 11. Hypothesis testing results.

\begin{tabular}{|c|c|c|c|c|c|c|}
\hline \multirow[b]{2}{*}{ Hypothesis } & \multirow[b]{2}{*}{ Path } & \multicolumn{2}{|c|}{ EOEL } & \multicolumn{2}{|c|}{ POEL } & \multirow[b]{2}{*}{ Result } \\
\hline & & SPC & t-Value & SPC & t-Value & \\
\hline $\mathrm{H} 1$ & $\mathrm{CF} \Longrightarrow \mathrm{US}$ & 0.536 & $3.926^{* * *}$ & 0.58 & $4.156^{* * *}$ & Supported (two-tailed test) \\
\hline $\mathrm{H} 2$ & $\mathrm{AF} \Longrightarrow \mathrm{US}$ & 0.202 & $1.974^{* * *}$ & 0.62 & $1.271^{0.204}$ & Non-Supported test \\
\hline H3 & $\mathrm{CF} \Longleftrightarrow \mathrm{AF}$ & 0.096 & $3.831^{* * *}$ & 0.14 & $5.102^{* * *}$ & Supported (two-tailed test) \\
\hline
\end{tabular}

Notes: $\mathrm{AF}=$ affective factors; $\mathrm{CF}=$ cognitive factors; $\mathrm{EOEL}=$ Expectation of e-learning website; $\mathrm{POEL}=$ Perception of e-learning website; SPC = Standardised path coefficient; US= Usability. ***)Significant with a significant value of 0.05 .

\subsubsection{Test of the structural model}

The results of the hypothesis tests and path coefficients of the proposed research model are shown in Table 11 and Figure 5 below.

In the case of expectation from an e-commerce website, out of the 12 preferred indicators of cognitive variables, only five were accepted, with the seven others failing to be decisive factors affecting cognitive variables. The indicator with the greatest loading factor 


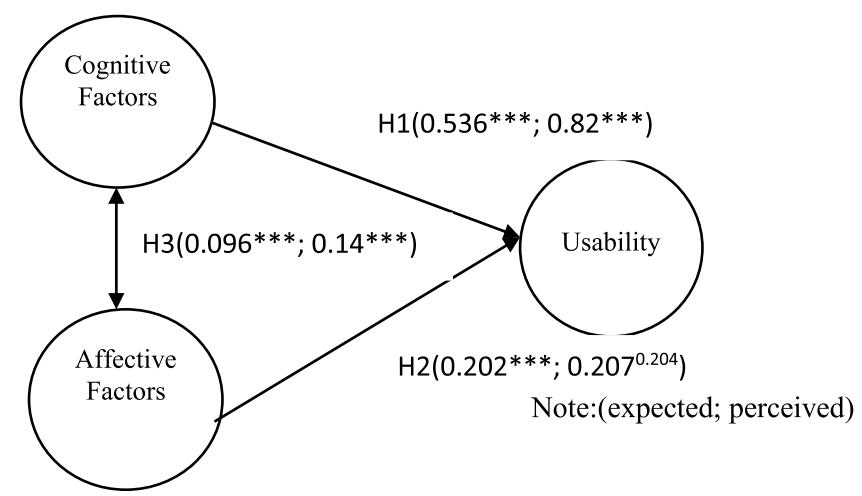

Figure 4. Standardised path coefficients for e-commerce.

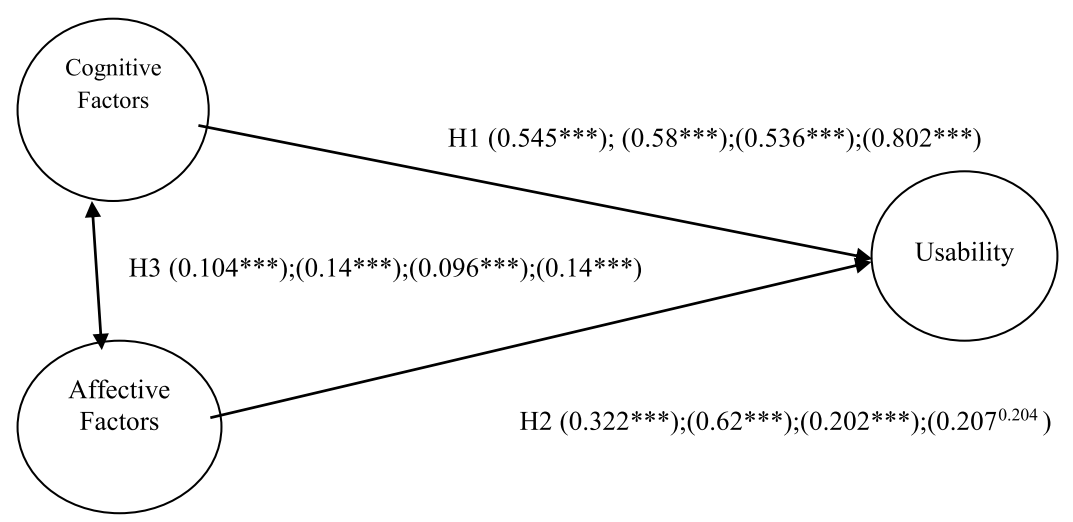

Figure 5. Visualization of loading factors in four website cases.

for the cognitive variable is error prevention 2 (EP2), with a value of 0.662 . Error prevention 2 is an indicator that shows whether or not the user can easily perform activities on the website.

The indicator with the greatest loading factor for the affective variable is brightness, at 0.895. Brightness is an indicator that measures whether the user feels that the website appears to be sufficiently bright. The value of Cronbach's alpha is greater than 0.70 , indicating that the variables consistently represent the formation variables developed.

Table 11 shows that hypotheses 1, 2 and 3 are accepted because they have significant p-values below 0.05 . The cognitive factor has a positive influence on the usability of the e-commerce website, with a value of 0.536 , which is greater than that of the affective factor.

On e-commerce sites, the indicator that has the largest factor for the cognitive variable is error prevention, with a value of 0.622 . Error prevention 1 is an indicator of whether users of the e-commerce sites report ease of activity on the site. The table also showed that the largest factor loading of the indicator variable is error prevention sites, which is also a cognitive factor. This result indicates that convenience of user activity on e-commerce sites has the greatest influence on e-commerce sites.

E-commerce sites can also be assessed using indicators with the largest loading factor of the affective variables, for which the value of harmony is equal to 0.692 . Harmoniousness is an indicator of whether users of e-commerce sites feel that the site experience has been 
harmonious. Table 11 shows that hypotheses 1 and 3 are accepted and that hypothesis 2 is rejected for the site. Hypothesis 1 is accepted because it has a significance value of below 0.05. Cognitive factors also have a positive effect on the usability of e-commerce sites, with a value of 0.802 for e-commerce sites.

In the case of e-commerce, the highest factors of expectation in the affective dimension are Salience, Comfort and Harmoniousness, whereas the highest factors of perception in the affective dimension are Comfort, Salience and Harmoniousness. The prominent indicators appear appropriate as well as between expected and perceived aspects.

Coursaris and van Osch (2015) also explains the relative importance of each aspect. There are several reasons that cause cognitive variables to significantly influence the usability of e-commerce websites. According to Lee and Kozar (2012), Content Relevance has the greatest influence on the attention of e-commerce users. Information on the product and the price clearly has a special attraction for users of e-commerce websites.

\section{Discussion}

\subsection{Usability model on the e-learning website}

Based on Table 5, of the 11 indicators of cognitive variables, nine have a sufficient loading factor: error prevention 1, 2 and 3, learnability, memorability, easy navigation, logical navigation, use of site direction and easy-to-go-back option. Further, of the eight indicators of affective variables, seven have a sufficient loading factor: colour, brightness, harmoniousness, salience, appeal and pleasantness, comfort and attractiveness. A significant difference is not observed between the effects on users of expected and perceived elements for the cognitive aspects of usability.

Factors of usability for the e-learning website were based on the factors studied previously by Zaharias and Poylymenakou (2009) on visual design subjects. These consist of convenience and ease of understanding the interface, including layout, colour, font and images. The factor of The Navigation Browsing covers activities on the website, and the use of features is the main aspect of such a factor. The aspect of accessibility summarises the access of website pages and features. Meanwhile, the factor of interactivity consists of all communication forms in the learning context facilitated by the system.

In prior studies, several authors concerned about affective factor in e-learning. Affective design in multimedia learning (Um et al. 2012; Plass et al. 2014); relationship between learner emotions and learning (e.g., Linnenbrink-Garcia, Rogat and Koskey 2011; Goetz et al. 2012), while Pekrun et al. (2002) found that pleasant emotions, like fun, lead to high achievement, while unpleasant emotions, such as test anxiety, lead to low achievement. In addition to affective factors, this paper discusses affective and cognitive factors.

\subsection{Usability model on e-commerce website}

Based on Table 9, of the 12 indicators of cognitive variables, those with sufficient loading factors include five indicators for expectation and six for perception: error prevention 1, 2 and 3 , interactivity, feedback and help 2, readability 1 , and consistency 1 and 2 . The six indicators of affective variables that have sufficient loading factors include two indicators for expectation and five for perception, among others, colour, brightness, harmoniousness, salience, comfort and attractiveness. 
Navigability, interactivity, learnability, readability and content relevance had a direct influence on cognitive aspects. The affective aspects of colour and brightness had an influence on expectations and on comfort, harmoniousness and salience, and comfort and harmoniousness are factors that influence purchase intention.

In the e-commerce website, cognitive factors have a significant impact on usability. The implications in the field are designed to maintain functional or cognitive considerations in the design of e-commerce websites. Elements that directly impact the access to necessary goods and transactions are a priority. This result is supported by previous research linking the cognitive aspects of system design and use-more specifically, efficiency and effectiveness-with an account of affective dimensions, including aesthetics and playfulness (Coursaris \& van Osch 2015). Although affective factors have no effect, the tendency towards influence began to appear at $\mathrm{p}=0.204$, but was non-significant.

\subsection{Overall usability model on e-learning and e-commerce websites}

The indicators for cognitive and affective variables used in evaluation of usability are not the same for both types of websites. The e-learning website is primarily used in the learning process, and, thus, the influences of emotional (affective) aspects are stronger. Cognitive factors are required as a condition to support e-learning, which relies heavily on information and communication media.

This study has shown that the affective aspect represents a usability factor to varying degrees. In the e-learning case, comparisons of the factor influences between affective and cognitive variables in usability measurement are 0.391:0.536 for expected and 0.322:0.545 for perceived elements. In the case of e-commerce, the comparison between affective and cognitive variables is 0.202:0.536 for expected and 0.207:0.802 for perceived elements. This shows that, in the case of the e-learning website, the affective process has more influence on usability than the cognitive one does.

E-commerce is used universally for every type of business or commercial transaction that includes information transmission via the Internet. E-commerce websites allow clients to purchase goods or services online through the Internet. Their expansion has made the assessment of the website usability experience highly relevant. One reason why the time required to interact with an e-learning website is longer than that required to interact with an e-commerce website is that the aim of the latter is to end the transaction.

The design of website usability is critical to e-learning and e-commerce success. This study identified website usability construct, and developed as well as validated measurement tools for this reason. Several interactions between website usability constructs and usability were discovered through causal mapping analysis and a questionnaire-based field study. Although challenges exist in the generalisability of our findings, this study successfully demonstrated that the identified constructs have strong psychometric properties based on a large amount of variance in usability. As shown in Table 12, this study first confirmed the presence of nomological networks between the cognitive and affective aspects and the usability. For all cases, we found that the cognitive aspect had a direct influence on usability. The cognitive aspect in the perception of e-commerce was the strongest factor in usability, indicating that creating indicators for cognitive factors has relevance for inducing usability. Error prevention, interactivity, feedback and help, readability, content relevance, and consistency became the main important considerations. 
Table 12. Summary of hypothesis testing results.

\begin{tabular}{lccccc}
\hline & & \multicolumn{2}{c}{ E-learning } & \multicolumn{2}{c}{ E-commerce } \\
\cline { 3 - 5 } Hypothesis & Path & Expected & Perceived & Expected & Perceived \\
\hline $\mathrm{H}_{1}$ & $\mathrm{CF} \rightarrow \mathrm{US}$ & $0.545^{* * *}$ & $0.58^{* * *}$ & $0.536^{* * *}$ & $0.802^{* * *}$ \\
$\mathrm{H}_{2}$ & $\mathrm{AF} \rightarrow \mathrm{US}$ & $0.322^{* * *}$ & $0.62^{* * *}$ & $0.202^{* * *}$ & $0.207^{0.204}$ \\
$\mathrm{H}_{3}$ & $\mathrm{CF} \rightarrow \mathrm{AF}$ & $0.104^{* * *}$ & $0.14^{* * *}$ & $0.096^{* * *}$ & $0.14^{* * *}$ \\
\hline
\end{tabular}

Note: (expected e-learning); (perceived e-learning); (expected e-commerce); (perceived e-commerce).

$\left.{ }^{* * *}\right)$ Significant with significant value of 0.05 .

The affective aspect in the perception of e-learning was the strongest factor in usability, indicating that affective aspects are relevant to usability. Harmoniousness, Salience, Comfort, and Attractiveness became the main important considerations. For the cognitive aspect, the findings are consistent with those of previous studies (DeLone and McLean 2004), noting that information quality is crucial, mainly for users who visit websites with utilitarian goals (e.g., to purchase products/services). Thus, customers will then perceive safety while purchasing products from the site.

The findings for affective aspects show that the associated indicators are highly supported. Indications show that the affective aspects contributed to the performance and were quite significant to usability, especially in the case of e-learning.

Figure 5 presents a visualisation of the loading factors for the cognitive and affective aspects of usability, equivalent to Table 12. The results of this research show that both the cognitive and affective dimensions are significant as predictors of usability. In the case of e-learning, the highest factor of expectation from the cognitive dimension is easy navigation, followed by logical navigation. This result is in line with the purpose of users who access this website. The factors of perception from the cognitive dimension are easy navigation, memorability and error prevention. The prominent indicators appear appropriate between expected and perceived elements. Although they are different indicators, the contribution of cognitive aspects to usability is in agreement with the general criteria for e-learning (Zaharias \& Poylymenakou 2009). The influence of the affective aspect on usability is highly important for addressing user needs. According to Coursaris and van Osch (2015), combining cognitive and affective dimensions is expected to result in the most comprehensive display for users, including usability.

This study offers several essential result findings for both researchers and practitioners. Theoretically, this work attempts to present a comprehensive exploration of the multifaceted elements of website usability, especially in e-learning and e-commerce. These instruments might be used in future usability studies, and the accumulated result can be directly compared. Therefore, the authors agree on the importance of website usability instrument development (Green \& Pearson 2002). The research confirms the complexity of a model in which cognitive, affective and cognitive-affective fundamentals are present, and advances knowledge on the consequences of usability and similarity with perceived interactivity (Cyr, Head, \& Ivanov 2009). The research found that the influence of perceived usability was mainly direct and less mediated by the affective dimensions (Porat \& Tractinsky 2012).

Second, this work suggests and validates nomological networks between website usability constructs and the absence of previous theoretical models of website usability. By examining the interactions among the usability constructs, we can identify the effect of each construct precisely. Therefore, the identified nomological networks can be used to enhance existing 
theoretical models or to develop alternative theoretical models of website usability to create a better understanding of the website usability phenomenon. Finally, although additional validation must be performed, the proposed model can be considered to be an alternative theoretical model of website usability. Through a series of empirical tests, the model was validated to explain many variances in customer online purchase intentions and purchases, implying that the model can be used in future studies to successfully measure the effect of website usability construction on online purchases.

Thus, the affective and cognitive aspects should be considered simultaneously. The human brain consists of two parts: logic and emotion. Both of these exercise different functions in determining our behavior, but the two are interdependent.

The practical implications of this study offer useful insights for product designers in considering cognitive aspects and also aid in identifying items for consideration in continuous improvement or planning as well as product development. The affective process refers to the emotional responses in a user's perceptions and feelings, and, thus, all of the processes related to usability rely on cognitive processing, whereas the semantic form uses affective processing (Hartono 2012).

This study has certain limitations that must be researched in future studies. First, the single-target websites used in this study do not represent all e-learning and e-commerce domains. Previous studies on information systems and marketing areas (Burke 2002) found that individual consumer beliefs, attitudes and behaviours were significantly influenced by different products, industries and technologies. Future studies with broader e-business domains are recommended. Second, the cognitive aspects were found to model website usability, but not the affective aspects. Several researchers have alluded to the ability of a website to stimulate emotional responses between consumers (Norman 2004). Therefore, it is suggested that future studies attend to the construction of other affective usability factors. Another limitation of this study is that the respondents are still clustered at the age of 17-22 years (students).

\section{Conclusions and further research}

Studies that consider the affective process as a complement to the cognitive process for usability are relatively scarce. To address this gap, this paper discusses how an integrative framework of the cognitive and affective aspects can be applied to a product for usability assessment via empirical studies on e-commerce and e-learning platforms. There are three validated constructs, of which two constructs affecting usability performance are the cognitive and affective aspects. One important finding showed that cognitive aspects still showed a strong influence on usability. However, the affective aspects also have a significant influence, to varying degrees, between e-commerce and e-learning. Considering the cognitive and affective aspects of web design simultaneously becomes necessary, the argument being that both are interdependent.

This research offers several potential contributions. First, the results can be used to determine the proportion of cognitive and affective aspects in product design, particularly those related to usability. Product designers can get feedback on how their design features affect user satisfaction by interpreting the relationship models. Second, for better usability, interface designs for e-learning and e-commerce websites must focus on the need for affective and cognitive aspects to improve usability. 
The results of this study have two implications for further research. First, to anticipate limited resources, further studies must focus on the additional indicators and affective aspects of applications in different websites and the most frequently used products in consumers' daily lives. Second, the affective aspects might vary based on age differences, professional groups and numbers of respondents that represent actual users and affective depth as behaviour brand considerations. Therefore, future studies must examine the applications of the model, either with different websites or different products, e.g., consumption of products such as tablets and gadgets and different (cultural-based) users.

\section{Disclosure statement}

No potential conflict of interest was reported by the authors.

\section{Notes on contributors}

Heru Prastawa is an Associate Professor, member on Work System Engineering and Ergonomic Laboratory, in Industrial Engineering, Diponegoro University. He earned B.S. in Mechanical Engineering from Sepuluh Nopember Institute (ITS) Surabaya, Masters in Technology Assessment from Universite Marseille III, Marseille, France. Graduate Student in Industrial Engineering from Sepuluh Nopember Institute (ITS) Surabaya. His research interests include Human Factors, Ergonomics, User Experience, and manufacturing System. He is member of IAE.

Udisubakti Ciptomulyono is a Professor and Senior Lecture at the Department of Industrial Engineering and for the time being he is Dean of Business and Management Technology in Institute of Technology Sepuluh November-Surabaya (ITS) Indonesia. He passed his Master Degree of Engineering Management and Development Technology in The University of Melbourne-Australia (1991) and hold Doctoral degree in Facultet des Sciences et Techniques de Saint Jerome-MarseilleFrance (2000). To date, Udisubakti has teaching responsibility for Graduate and Doctoral student Program in many Departments of ITS, courses taught: Multiple Criteria Decision Making, System Modelling and Analysis, Management of Technology, Sustainable Manufacturing and Environmental Management. He has published more than 75 journal and conferences papers and focussed his research interest in area of Multi Criteria Decision Making and its applications, Management Innovation and Technology Policy, Environmental Energy and Sustainable Manufacturing.

Moses Laksono Singgih is a Professor and senior lecture at the Department of Industrial Engineering. He received his Bachelor of Engineering (B.Eng) in Industrial Engineering from Institute Technology of Bandung (ITB) He passed his Master Doctoral degree in University of Queensland, Australia. To date, Moses has teaching responsibility for Graduate and Doctoral student Program in many Departments of ITS, courses taught: Sustainable Manufacturing and Environmental Management, Quality Management, and Advanced Manufacturing System.

Markus Hartono is an Associate Professor at the Department of Industrial Engineering, University of Surabaya, Indonesia. He received his Bachelor of Engineering (B.Eng.) in Industrial Engineering from University of Surabaya (Ubaya), Indonesia, in 2000 with predicate of Cum Laude. In 2004, he received the ASEAN Graduate Scholarships (AGS) award for pursuing his master's degree in Industrial and Systems Engineering from National University of Singapore (NUS), and he obtained his Master of Science (M.Sc.) in 2005. In 2008, he received a prestigious award of NUS Graduate Research Scholarships for 4 years for pursuing his $\mathrm{PhD}$, and obtained his $\mathrm{PhD}$ degree in 2012. He received Best Paper Award of the 14th \& 15th Quality in Research (QiR) in 2015 and 2017, respectively. He has published more than 20 research articles in top tier international journals and reputable international conferences. His teaching and research interest is in ergonomics, product design and management, Kansei Engineering, and time and motion study. He is a Certified Human Factors Professional (CHFP), a member of IEA Affective Design Technical Committees, and Vice President of Indonesian Ergonomics Society (IES) 2015-2018. 


\section{References}

Ackerman, R., A. Parush, F. Nassar, A. Shtub. 2016. "Metacognition and system usability: Incorporating metacognitive research paradigm into usability testing." Computers in Human Behavior 54: 101-113.

Adams, R. 2007. "Decision and Stress: Cognition and e-Accessibility in the Information Workplace." Universal Access in the Information Society 5 (4): 363-79. doi:10.1007/s10209-006-0061-9.

Alexandre, G., and N. Mandonnet. 2012. "Testing a Model of User-experience with News Website Questioning the resilience of goat production in the Tropics at different levels from the animal to the whole system." International conference on goats. 153.

Aranyi, G., and P. van Schaik. 2016. "Testing a Model of User-experience with News Websites." Journal of the Association for Information Science and Technology 67 (7): 1555-1575.

Asil, O., N. Alexander, and Z. Selim. 2009. "UWIS: An Assessment Methodology for Usability of Web Based Information Systems." The Journal of Systems and Software 82: 2038-2050.

Asil, O., James Kong, Z. O. Uysal. 2010. "UseLearn: A Novel Checklist and Usability Evaluation Method for eLearning Systems by Criticality Metric Analysis." International Journal of Industrial Ergonomics, 4: 455-469.

Berry, J. W., E. L. Worthington, L. E. O’Connor, L. Parrott, and N. G. Wade. 2005. "Forgivingness, vengeful rumination, and affective traits." Journal of Personality 73 (1): 183-226.

Bonnardel, N., A. Piolat, L. Le Bigot. 2011. "The Impact of Colour on website appeal and users' Cognitive Processes.” Display 32(2): 69-80. Doi:10.1016/j.displa.2010.12.002.

Burke, R. R. 2002. "Technology and the Customer Interface: What Consumers Want in the Physical and Virtual Store." Journal of the Academy of Marketing Science 304: 411-432.

Clark, R. C., and R. E. Mayer. 2003. E-learning and the science of instruction: Proven guidelines for consumers and designers of multimedia learning. San Francisco, California: Jossey-Bass/Pfeiffer

Coursaris, C. K., and W. van Osch. 2015. "A Cognitive-Affective Model of Perceived User Satisfaction (CAMPUS): The Complementary Effects and Interdependence of Usability and Aesthetics in IS Design.” Information \& Management 53 (2): 252-264. doi:10.1016/j.im.2015.10.003.

Cyr, D., M. Head, and A. Ivanov. 2009. "Perceived Interactivity Leading to e-loyalty: Development of a Model for Cognitive-affective User Responses." International Journal of Human-Computer Studies 67 (10): 850-869. doi:10.1016/j.ijhcs.2009.07.004.

Davis, F. D., R. P. Bagozzi, and P. R. Warshaw. 1992. "Extrinsic and Intrinsic Motivation to Use Computers in the workplace1." Journal of Applied Social Psychology 22 (14): 1111-1132. doi:10.1111/j.1559-1816.1992.tb00945.x.

De Lone, W. D., and E. R. McLean. 2004. "Measuring e-commerce Success: Applying the DeLone and McLean Information Systems Success Model." International Journal of Electronic Commerce 9 (1): 31-47.

Demirtas, E. A., A. S. Anagun, and G. Koksal. 2009. "Determination of Optimal Product Styles by Ordinal Logistic Regression versus Conjoint Analysis for Kitchen Faucets." International Journal of Industrial Ergonomics 39 (5): 866-875.

Fagerberg, P., A. Stahl, and K. Hook. 2004. “eMoto: Emotionally Engaging Interaction.” Pers Ubiquit Comput 8: 377-81.

Goetz, T., U. E. Nett, S. E. Martiny, N. C. Hall, R. Pekrun, S. Dettmers, and U. Trautwein. 2012. "Students' Emotions during Homework: Structures, self-concept Antecedents, and Achievement Outcomes." Learning and Individual Difference 22 (2): 225-234. doi:10.1016/j.lindif.2011.04.006.

Green, D., and J. M. Pearson. 2004. "A Confirmatory Factor Analysis of Two Web Site Usability Instruments." Proceedings of 3rd Pre-ICIS Annual Workshop on HCI Research in MIS, Washington, DC, 35-39.

Han, S. H., M. H. Yun, J. Kwahk, and S. W. Hong. 2001. "Usability of Consumer Electronic Products." International Journal of Industrial Ergonomics 28 (3-4): 143-151. doi:10.1016/S01698141(01)00025-7.

Hariri, N., and Y. Norouzi. 2011. 'Determining Evaluation Criteria for Digital Libraries' User Interface: A Review." The Electronic Library 29 (5): 698-722. doi:10.1108/02640471111177116.

Hartmann, J., A. Sutcliffe, and A. De Angeli. 2008. "Towards a theory of user judgment of aesthetics and user interface quality." Transactions on Computer-Human Interaction 15 (3): 429-452. 
Hartono, M., A. Sutcliffe, and A. De Angeli. 2012. "Incorporating Markov Chain Modelling and QFD into Kansei Engineering Applied to Services Tan Kay Chuan Shigekazu Ishihara." IJHFE 1 (1): 74-97.

Hassenzahl, M., 2004. "The Interplay of Beauty, goodness, and Usability in Interactive Products." Human-Computer Interaction 19 (4): 319-349.

Hassenzahl, M., A. Monk. 2010. "The inference of perceived usability from beauty." J Human Computer Interaction. 25 (3): 235-260.

Heidig, S., J. Müller, and M. Reichelt. 2015. "Emotional Design in Multimedia Learning: Differentiation on Relevant Design Features and Their Effects on Emotions and Learning." Computers in Human Behavior 44: 81-95. doi:10.1016/j.chb.2014.11.009.

Hsiao, K., and L. Chen. 2006. "Fundamental dimensions of afektif responses to product shapes." International Journal of Industrial Ergonomics 36: 553-564. doi:10.1016/j.ergon.2005.11.009.

Huang, Y., C. Chen, and L. P. Khoo. 2012. "Products Classification in Emotional Design Using a Basic-emotion Based Semantic Differential Method." International Journal of Industrial Ergonomics 42 (6): 569-580. doi:10.1016/j.ergon.2012.09.002.

Johnson, D., F. Johnson. 2006. "Joining together; Team theory and team skills." (9th edition). Englewood Cliffs: Prentice-Hall.

Joo, J., and Y. Sang. 2013. “Exploring Koreans' Smartphone Usage: An Integrated Model of the Technology Acceptance Model and Uses and Gratifications Theory." Computers in Human Behavior 29 (6): 2512-2518.

Kim, H. K., S. H. Hana, J. Park, J. Park. 2016. "Identifying Affect Elements Based on a Conceptual Model of Affect: A Case Study on a Smartphone." International Journal of Industrial Ergonomics 53: 193-204

Korgaonkar, P., and L.D. Wolin. 1999. "Web usage, advertising and shoping : Relationship pattern.” Internet Research 12(2): 191-204.

Kwahk, J., and S. H. Han. 2002. "A Methodology for Evaluating the Usability of Audiovisual Consumer Electronic Products." Applied Ergonomics 33 (5): 419-431.

Kwong, T., M.D. Cox, K. Chong, W. L. Wong, S. Nie. 2016. "Assesing the Effect of Communities of Practice in Higher Education: The case at Hongkong Baptist University." Learning Communities Journal 8 (2): 171-198.

Lavie, T., and N. Tractinsky. 2004. "Assessing Dimensions of Perceived Visual Aesthetics of Web sites." International Journal of Human-Computer Studies 60 (3): 269-298.

Lee, Y., and K. Kozar. 2012. "Understanding of Website Usability: Specifying and Measuring Constructs and Their Relationships." Decision Support Systems 52 (2): 450-463.

Lewalski, Z., 1998. "Product Esthetic - An Interpretation for Designer." Design \& Development Engineering Press, Carson City.

Lewis, J. R. 2015. "Introduction to the Special Issue on Usability and User Experience: Psychometrics." International Journal of Human-Computer Interaction 31 (8): 481-483.

Li, G., C. Li. 2011. “Efficient Fuzzy ful-text type ahead Search.” VLDB J. 20 (4): 617-640.

Liljegren, E., and A. Osvalder. 2004. "Cognitive Engineering Methods as Usability Evaluation Tools for Medical Equipment." International Journal of Industrial Ergonomics 34 (1): 49-462.

Linnenbrik-Garcia, E. A., T. K., Rogat, and K. L. Koskey. 2011. "Affect and Engagement during Small Group Instruction." Contemporarry Educational Psychology. 36: 13-24.

Nielsen, J. 1993. Usability Engineering. London: Academic Press.

Norman, D. A. 2004. Emotional Design: Why We Love or Hate Everyday Things. New York: Basic Books.

Palacio, R. R., C. O. Acosta, J. Cortez, and A. L. Morán. 2017. "Usability Perception of Different Video Game Devices in Elderly." Universal Access in the Information Society 16: 103-113.

Park, J., and S. H. Han. 2013. "Defining User Value: A Case Study of a Smartphone." International Journal of Industrial Ergonomics 43 (4): 274-282.

Park, J., S. H. Han, H. K. Kim, S. Oh, and H. Moon. 2013. "Modeling User Experience: A Case Study on a Mobile Device." International Journal of Industrial Ergonomics 43 (2): 187-196.

Pekrun, R., T. Goetz, W. Titz, and R. P. Perry. 2002. "Academic Emotions in Students'self-regulated Learning and Achievement: A Program of Qualitative and Quantitative Research.” Educational Psychologist 37 (2): 91-105. 
Pengnate, S. F., and R. Sarathy. 2017. "An Experimental Investigation of the Influence of Website Emotional Design Features on Trust in Unfamiliar Online Vendors." Computers in Human Behavior 67: 49-60.

Plass, J. L., S. Heidig, E. O. Hayward, B. D. Homer, and E. Um. 2014. "Emotional design in multimedia learning: Effects and shape and color affect and learning." Learning and Instruction. 29: 128-140.

Porat, T., and N. Tractinsky. 2012. "It's a Pleasure Buying Here: The Effects of Web-Store Design on Consumers' Emotions and Attitudes." Human-Computer Interaction 27: 235-276.

Quinn, J. M., and T. Q. Tran. 2010. "Attractive Phones Don't Have To Work Better: Independent Effects of Attractiveness, Effectiveness, and Efficiency on Perceived Usability." CHI'10: Proceedings of the 28th International Conference on Human Factors in Computing Systems (pp. 353-362). New York, NY: ACM.

Rakefet, A., P. Avi, N. Fareda, and S. Avraham. 2016. "Metacognition and System Usability: Incorporating Metacognitive Research Paradigm into Usability Testing." Computers in Human Behavior 54: 101-113.

Riva, G., T. Teruzzi, and L. Anolli. 2003. "The Use of the Internet in Psychological Research: Comparison of Online and Offline Questionnaires." Cyberpsychology \& Behavior 6 (1): 73-80. doi:10.1089/109493103321167983.

Rubin, J., and D. Chisnell. 2008. "Handbook of Usability Testing: How to Plan, Design and Conduct Effective Test." Human-Computer Interaction 27: 235-276.

Savioja, P., and L. Norros. 2013. "Systems Usability Framework for Evaluating Tools in Safety - critical Work."15: 255-275.

Seva, R. R., K. G. T. Gosiaco, M. Crea, E. D. Santos, and D. M. L. Pangilinan. 2011. "Product Design Enhancement Using Apparent Usability and Affective Quality." Applied Ergonomics 42 (3): 511517. doi:10.1016/j.apergo.2010.09.009.

Sonderegger, A., S. Schmutz, and J. Sauer. 2016. “The Influence of Age in Usability Testing.” Applied Ergonomics 52 (5): 291-300.

Suárez, 2016. "Investigating Website Appearance and Usability Effects on Student Satisfaction with the Website: A Descriptive Analysis in Three Countries." International Review on Public Nonprofit Mark 1: 223-238.

Tsai, M.R., Y.W. Chiou, M.T Lo, C.K. Sun. 2010. "Second harmonic generation imaging of collagen fibers in mycocardium for atrial fibrillation diagnosis." Human-Computer Interaction 15(2): 026052.

Tuch, A. N., S. P. Roth, K. Hornbaek, K. Opwis, and J. A. Bargas-Avila. 2012. "Is Beautiful Really Usable? Toward Understanding the Relation between Usability, aesthetics, and Affect in HCI." Computers in Human Behavior 28 (5): 1596-607.

Um, H. N., J. M. Han, J. I. Hwang, S. I. Hong, H. Vaundry, J. Y. Seong. 2010. "Molecular coevolution of kisspeptin and their reception from fish to mammals." Ann N.Y. Academic Sciences. 1200, 6774. Doi:10.1111/j1749-6632.2010.05508.x.

van Schaik, P., and J. Ling. 2009. "The Role of Context in Perceptions of the Aesthetics of Web Pages over Time." International Journal of Human-Computer Studies 67 (1): 79-89.

Zaharias, P., and A. Poylymenakou. 2009. "Developing a Usability Evaluation Method for e-learning Applications: Beyond Functional Usability." International Journal of Human-Computer Interaction 25 (1): 75-98.

Zhou, X., R. Panizzuti, E. De Villers-Sidani, C. Johnson, and M.M. Meraenich. 2011. "Natural restoration of critical period plasticity in juvenile and adult primary auditory cortex." J. Neurosci 31: 5625-5634. doi:10.1523/JNEUROSCI.6470-10.2011. 


\section{Appendix (revised)}

Indicators variables and source (e-learning).

\begin{tabular}{|c|c|c|c|}
\hline Variables & Cognitive indicators & Operational definition/ questionnaires Item & Source \\
\hline $\mathrm{X} 1$ & Error Prevention 1/EP1 & Can multiple but similar tasks be done easily? & Asil et al. (2010) \\
\hline $\mathrm{X} 2$ & Error Prevention 2/EP2 & $\begin{array}{l}\text { Can the user easily undo selections, actions, errors } \\
\text { in arrangement or management of items? }\end{array}$ & \\
\hline $\mathrm{X} 3$ & Error Prevention 3/EP3 & $\begin{array}{l}\text { Do error or warning messages prevent possible } \\
\text { errors from occurring? }\end{array}$ & \\
\hline X4 & $\begin{array}{l}\text { Interactivity, Feedback, } \\
\text { and Help1/IFH1 }\end{array}$ & $\begin{array}{l}\text { Does the menu offer multiple opportunities for } \\
\text { interaction and communication among the } \\
\text { user, to the instructor and to content? }\end{array}$ & \\
\hline $\mathrm{X} 5$ & Learnable/LEAR & $\begin{array}{l}\text { Is the website already presenting appropriate } \\
\text { information related to products sold? }\end{array}$ & \\
\hline $\mathrm{X} 6$ & Readablity/READ & $\begin{array}{l}\text { Is the website already serving "sentences" that are } \\
\text { easy to understand and clear? }\end{array}$ & \\
\hline $\mathrm{X7}$ & Memorability/MEMO & Are steps of using e-learning easy to remember? & Lee and Kozar (2012) \\
\hline $\mathrm{X} 8$ & Easy Navigation/ENAV & $\begin{array}{l}\text { Is the website already presenting an existing guide } \\
\text { to operate e-learning is easy to run? }\end{array}$ & \\
\hline X9 & Logical Navigation/LNAV & $\begin{array}{l}\text { Is the website already presenting an existing guide } \\
\text { to operate e-learning which is logical to run? }\end{array}$ & \\
\hline $\mathrm{X} 10$ & $\begin{array}{l}\text { Understable Site } \\
\text { Direction/UNSD }\end{array}$ & $\begin{array}{l}\text { Is the website already serving a similar display } \\
\text { design on every page of its web? }\end{array}$ & \\
\hline $\mathrm{X} 11$ & $\begin{array}{l}\text { Easy Get Back Option/ } \\
\quad \text { EGBO }\end{array}$ & $\begin{array}{l}\text { Is the website already presenting option to return } \\
\text { to the previous page? }\end{array}$ & \\
\hline
\end{tabular}

\begin{tabular}{|c|c|c|c|}
\hline \multirow[b]{2}{*}{$\underline{\text { Variables }}$} & \multicolumn{3}{|c|}{ Operational definition/ questionnaires } \\
\hline & Affective indicators & Item & Source \\
\hline $\mathrm{X} 12$ & Color/COL & $\begin{array}{l}\text { Does color become the conceptual } \\
\text { image of the site }\end{array}$ & \\
\hline $\mathrm{X} 13$ & Brightness/BR & $\begin{array}{l}\text { Whether brightness is part of the } \\
\text { conceptual image of the site }\end{array}$ & $\begin{array}{l}\text { Park and Han (2013), } \\
\text { Han et al. (2001) }\end{array}$ \\
\hline $\mathrm{X} 14$ & Harmoniousness/HR & $\begin{array}{l}\text { Whether compatibility and alignment } \\
\text { are part of the site's considerations. }\end{array}$ & \\
\hline $\mathrm{X} 15$ & Salience/SL & $\begin{array}{l}\text { Whether the convenience of using the } \\
\text { site is a conceptual image }\end{array}$ & \\
\hline $\mathrm{X} 16$ & $\begin{array}{l}\text { Appealing and Pleasant/ } \\
\quad \text { APPL }\end{array}$ & $\begin{array}{l}\text { Is the appearance of e-learning } \\
\text { interesting and does it arouse user } \\
\text { interest? }\end{array}$ & \\
\hline $\mathrm{X} 17$ & Comfort/COMF & $\begin{array}{l}\text { Whether the convenience of using the } \\
\text { site is a conceptual image }\end{array}$ & \\
\hline $\mathrm{X} 18$ & Reliability/RELI & $\begin{array}{l}\text { Do you feel the website reliable and be } \\
\text { trusted? }\end{array}$ & \\
\hline $\mathrm{X} 19$ & Attractiveness/ATTR & $\begin{array}{l}\text { Do you feel the website attractive and } \\
\text { pleasing? }\end{array}$ & \\
\hline
\end{tabular}

\begin{tabular}{|c|c|c|c|}
\hline Variables & Indicator & $\begin{array}{l}\text { Operational definition/ } \\
\text { questionnaires Item }\end{array}$ & \\
\hline $\mathrm{X} 19$ & Effectiveness & $\begin{array}{l}\text { Are you able to operate e-learning } \\
\text { accurately and perfectly? }\end{array}$ & $\begin{array}{l}\text { Han et al. (2001), Asil et al. } \\
\text { (2010) }\end{array}$ \\
\hline $\mathrm{X} 20$ & Efficiency & $\begin{array}{l}\text { Are you facilitated in completing its } \\
\text { objectives quickly, effectively and } \\
\text { economically? }\end{array}$ & $\begin{array}{l}\text { Han et al. (2001), Asil et al. } \\
\quad(2010)\end{array}$ \\
\hline $\mathrm{X} 21$ & Satisfaction & Are you satisfied after using e-learning? & $\begin{array}{l}\text { Han et al. (2001), Asil et al. } \\
\text { (2010) }\end{array}$ \\
\hline
\end{tabular}


Indicators variables and source (e-commerce).

\begin{tabular}{|c|c|c|c|}
\hline Variables & Cognitive indicators & Operational definition/ questionnaires Item & Source \\
\hline $\mathrm{X} 1$ & Error Prevention 1/EP1 & Can multiple but similar tasks be done easily? & Asil et al. (2010) \\
\hline $\mathrm{X} 2$ & Error Prevention 2/EP2 & $\begin{array}{l}\text { Can the user easily undo selections, actions, } \\
\text { errors in arrangement or management of } \\
\text { items? }\end{array}$ & \\
\hline X3 & Error Prevention 3/EP3 & $\begin{array}{l}\text { Do error or warning messages prevent } \\
\text { possible errors from occurring? }\end{array}$ & \\
\hline $\mathrm{X} 4$ & $\begin{array}{l}\text { Interactivity, Feedback, } \\
\text { and Help1/IFH1 }\end{array}$ & $\begin{array}{l}\text { Does the menu offer multiple opportunities } \\
\text { for interaction and communication among } \\
\text { users, to the instructor, and to content? }\end{array}$ & \\
\hline $\mathrm{X} 5$ & $\begin{array}{l}\text { Interactivity, Feedback } \\
\text { and Help } 2 \text { /IFH2 }\end{array}$ & $\begin{array}{l}\text { Is regular feedback about user performance } \\
\text { provided in a timely manner? }\end{array}$ & \\
\hline $\mathrm{X} 6$ & $\begin{array}{l}\text { Interactivity, Feedback } \\
\text { and Help } 3 \text { /IFH3 }\end{array}$ & $\begin{array}{l}\text { Is the user provided with sufficient information } \\
\text { to know where in the system he/she is? }\end{array}$ & \\
\hline $\mathrm{X} 7$ & Readability 1/ RD1 & $\begin{array}{l}\text { Is the website already serving "sentences" that } \\
\text { are easy to understand and clear? }\end{array}$ & Lee and Kozar (2012) \\
\hline $\mathrm{x} 8$ & Readability 2/RD2 & $\begin{array}{l}\text { Is the website already presenting sufficient } \\
\text { margin spacing between sentences so it is } \\
\text { easy to read? }\end{array}$ & \\
\hline X9 & Content Relevance 1 /CR1 & $\begin{array}{l}\text { Is the website already presenting appropriate } \\
\text { information related to products sold? }\end{array}$ & \\
\hline $\mathrm{X} 10$ & Content Relevance 2/CR2 & $\begin{array}{l}\text { Is the website already presenting up to date } \\
\text { and accurate information related to } \\
\text { products sold? }\end{array}$ & \\
\hline $\mathrm{X} 11$ & Consistency $1 / \mathrm{CS} 1$ & $\begin{array}{l}\text { Is the website already serving a similar display } \\
\text { design on every page of its web? }\end{array}$ & \\
\hline $\mathrm{X} 12$ & Consistency $2 / \mathrm{CS} 2$ & $\begin{array}{l}\text { Is the website already presenting similar } \\
\text { components in each web page? }\end{array}$ & \\
\hline
\end{tabular}

\begin{tabular}{|c|c|c|c|}
\hline Variables & Affective indicators & $\begin{array}{l}\text { Operational definition/ questionnaires } \\
\text { Item }\end{array}$ & Source \\
\hline $\mathrm{X} 13$ & Color/COL & $\begin{array}{l}\text { Does color become the conceptual image } \\
\text { of the site }\end{array}$ & $\begin{array}{l}\text { Park and Han (2013), } \\
\text { Han et al. (2001) }\end{array}$ \\
\hline $\mathrm{X} 14$ & Brightness/BR & $\begin{array}{l}\text { Whether brightness is part of the } \\
\text { conceptual image of the site }\end{array}$ & \\
\hline $\mathrm{X} 15$ & Harmoniousness/HR & $\begin{array}{l}\text { Whether compatibility and alignment are } \\
\text { part of the site's considerations. }\end{array}$ & \\
\hline $\mathrm{X} 16$ & Comfort / COM & $\begin{array}{l}\text { Whether the convenience of using the site } \\
\text { is a conceptual image }\end{array}$ & \\
\hline $\mathrm{X} 17$ & Acceptability/ACCP & $\begin{array}{l}\text { Do site users feel easy and comfortable } \\
\text { with a product? }\end{array}$ & \\
\hline $\mathrm{X} 18$ & Neatness/NEAT & $\begin{array}{l}\text { Whether the use of a fun and acceptable } \\
\text { site is a conceptual image. }\end{array}$ & \\
\hline
\end{tabular}

\begin{tabular}{llcl}
\hline Variables & \multicolumn{1}{c}{ Indicator } & Operational definition/ questionnaires & \\
X19 & Effectiveness & $\begin{array}{c}\text { Are you able to operate e-commerecd } \\
\text { accurately and perfectly? } \\
\text { Are you facilitated in completing its } \\
\text { objectives quickly, effectively and } \\
\text { economically? }\end{array}$ & Han et al. (2001), Asil et al. (2010) \\
& Efficiency & Han et al. (2001), Asil et al. (2010) \\
X21 & Satisfaction & $\begin{array}{c}\text { Are you satisfied after using } \\
\text { e-commerce? }\end{array}$ & Han et al. (2001), Asil et al. (2010) \\
\hline
\end{tabular}

